\title{
Baseline Anti-Citrullinated Protein Antibody Status and Response to Abatacept or Non-TNFi Biologic/ Targeted-Synthetic DMARDs: US Observational Study of Patients with RA
}

Leslie R. Harrold · Sean E. Connolly · Keith Wittstock •

Joe Zhuo · Sheila Kelly $\cdot$ Thomas Lehman · Ying Shan •

Sabrina Rebello $\cdot$ Lin Guo $\cdot$ Vadim Khaychuk

Received: August 10, 2021 / Accepted: November 15, 2021 / Published online: December 23, 2021

(C) The Author(s) 2021

\section{ABSTRACT}

Introduction: Patients with rheumatoid arthritis (RA) may respond to treatments differently based on their underlying serology and

Supplementary Information The online version contains supplementary material available at https:// doi.org/10.1007/s40744-021-00401-0.

Sabrina Rebello affiliated "CorEvitas, LLC, Waltham, MA, USA" at the time of study.

L. R. Harrold $(\varangle) \cdot$ S. Rebello

CorEvitas, LLC, Waltham, MA, USA

e-mail: lharrold@corevitas.com

L. R. Harrold

University of Massachusetts Medical School,

Worcester, MA, USA

S. E. Connolly · S. Kelly · T. Lehman

Bristol Myers Squibb, Princeton, NJ, USA

K. Wittstock

US Immunology, Bristol Myers Squibb, Princeton,

NJ, USA

J. Zhuo

Worldwide Health Economics and Outcomes

Research, Bristol Myers Squibb, Princeton, NJ, USA

Y. Shan · L. Guo

Department of Biostatistics, CorEvitas, LLC,

Waltham, MA, USA

V. Khaychuk

US Medical Immunology and Fibrosis, Bristol Myers

Squibb, Princeton, NJ, USA biomarker status, but real-world data comparing treatment responses to abatacept versus other non-TNFi biologic or targeted-synthetic DMARDs by anti-citrullinated protein antibody (ACPA) status remain limited. We assessed the association between ACPA status and response to treatment in patients with RA.

Methods: Adults from CorEvitas' RA Registry were identified who initiated abatacept, rituximab, tocilizumab, or tofacitinib, and had ACPA measured at/prior to treatment initiation and at the 6-month follow-up visit. Three cohorts were included: abatacept/rituximab (2006-2019), abatacept/tocilizumab (2010-2019), and abatacept/tofacitinib (2012-2019). Patient characteristics at initiation were compared by ACPA status (positive $[+]$, anti-cyclic citrullinated peptide-2 [anti-CCP2] $\geq 20 \mathrm{U} / \mathrm{ml}$; negative [-], anti-CCP2 $<20 \mathrm{U} / \mathrm{ml}$ ). Outcomes over 6 months: changes in Clinical Disease Activity Index (CDAI), modified Health Assessment Questionnaire (mHAQ), patient global assessment (PGA) scores, and proportion of patients achieving a clinical response. Adjusted mean differences and odds ratios were estimated using mixed-effects linear regression models.

Results: Overall, 982 abatacept, 246 rituximab, 404 tocilizumab, and 429 tofacitinib initiators were identified. ACPA+ (vs. ACPA-) patients had longer disease duration and more erosive disease. During most time periods adjusted mean changes in CDAI, mHAQ, and PGA scores and the proportion of patients achieving a 
clinical response were significantly higher for $\mathrm{ACPA}+$ versus ACPA- patients initiating abatacept. Adjusted mean change in PGA score and patient fatigue were significantly higher for $\mathrm{ACPA}+$ versus ACPA- patients initiating rituximab. No significant differences were seen by ACPA status for patients initiating tocilizumab or tofacitinib.

Conclusions: Patients who initiated abatacept or rituximab and were ACPA+ had a greater clinical response at 6-month follow-up post index compared to patients who were ACPA - treated with the same biologic.

Keywords: Anti-cyclic citrullinated antibodies; Biological therapy; Disease-modifying antirheumatic drugs; Outcome assessment; Rheumatoid arthritis

\section{Key Summary Points}

Why carry out this study?

Serology and biomarker status may impact treatment response in patients with rheumatoid arthritis (RA): Patients with anti-citrullinated protein antibody (ACPA) positive (+) RA are more likely to develop more severe, erosive disease than patients who are ACPA negative (-).

The objective of this study was to evaluate the association of baseline ACPA status with response to treatment with abatacept or other non-TNFi b/tsDMARDs in patients with RA in a real-world setting.

What was learned from the study?

ACPA positivity was associated with a greater clinical response at 6 months among patients who initiated abatacept or rituximab compared to those who were ACPA - treated with the same biologic; no association was observed between patients with ACPA+ and ACPA- RA treated with tocilizumab or tofacitinib.
Based on underlying serology, patients with RA may respond differently to treatments with different mechanisms of action.

These results, and future studies, help clinicians develop individualized treatment plans for patients with RA.

\section{INTRODUCTION}

Seropositive rheumatoid arthritis (RA) is characterized by the production of autoantibodies, including rheumatoid factor (RF) and anticitrullinated protein antibodies (ACPAs) [1]. The presence of ACPAs may indicate poor prognosis in patients with RA. Patients with RA who are ACPA-positive (ACPA+) are more likely to develop severe, erosive disease than those who are ACPA-negative (ACPA-) [2, 3]. The European Alliance of Associations for Rheumatology and American College of Rheumatology (ACR) treatment guidelines recommend clinicians adopt a treat-to-target approach to manage the treatment of patients with RA $[4,5]$. Serological markers, such as ACPAs, are useful in this approach.

Data from several studies have indicated that response to abatacept or tumor necrosis factor inhibitor (TNFi) RA therapy may vary based on ACPA status [6-9]. In a post hoc analysis of the 2-year AMPLE (Abatacept vs adaliMumab comParison in bioLogic naïvE RA subjects with background methotrexate) study, patients treated with abatacept or a TNFi who were ACPA+ experienced greater improvement in disease activity and physical disability than patients who were ACPA- [7]. Additionally, patients with the highest baseline ACPA concentrations had a better clinical response to abatacept than patients with lower concentrations, an effect not seen with TNFi treatment [7]. In a post hoc analysis of the AVERT (Assessing Very Early Rheumatoid arthritis Treatment) study in patients with RA who were ACPA immunoglobin (Ig) G+ at baseline, abatacept plus methotrexate (MTX) had greater clinical efficacy in those who were also ACPA 
IgM+ at baseline compared with patients who were ACPA IgM- [8].

The Pan-European Registry analysis of nine observational RA registries in Europe determined that patients who were ACPA+ had a significantly lower risk of discontinuation of abatacept for any reason or due to ineffectiveness of treatment compared with patients who were ACPA- [10]. A pooled analysis of over 27,000 patients from 16 observational RA registries demonstrated that RA and/or ACPA seropositivity was associated with increased effectiveness and decreased discontinuation rates of non-TNFi biologic disease-modifying antirheumatic drugs (bDMARDs; including abatacept), but this was not seen with TNFis [11].

An analysis from CorEvitas' RA Registry, using data collected from clinical practice settings in the US, has shown that patients with $\mathrm{ACPA}+\mathrm{RA}$ had a greater clinical response to treatment with abatacept, but not to a TNFi, than patients with ACPA- RA [9]. The analysis showed improvements in Clinical Disease Activity Index (CDAI) and modified Health Assessment Questionnaire (mHAQ; a modification of the standard HAQ where the number of activities of daily living assessed was reduced from 20 to 8 ) scores and the proportion of patients achieving CDAI remission (CDAI $\leq 2.8$ ) or low disease activity (LDA; CDAI $\leq 10$ ) at 6 months were all significantly greater among patients treated with abatacept who were ACPA+ compared with those who were ACPA- [9]. In another prior analyses from CorEvitas' RA Registry, all patients with ACPA+ RA (either bDMARD-naïve or -experienced) showed improvements in clinical disease activity in response to treatment with abatacept or a TNFi [12]. However, among those who were bDMARD-experienced, patients treated with abatacept had significantly greater improvements in clinical outcomes than patients treated with a TNFi [12].

Patients may respond differently to different treatments based on their underlying serology and biomarker status, but real-world data comparing treatment responses to abatacept versus other non-TNFi biologic or targeted-synthetic (b/ts) DMARDs by ACPA status remain limited.
This US national observational study used data from CorEvitas' RA Registry to assess whether baseline ACPA status was associated with response to treatment with abatacept or other non-TNFi b/tsDMARDs in patients with RA.

\section{METHODS}

\section{Data Source}

CorEvitas' RA Registry is an independent, prospective, national, observational cohort in which treatment and outcomes data for patients with RA are collected and analyzed. Patients were recruited from 180 private practices and academic sites with 769 participating rheumatologists across 42 states in the US. As of June 2020, the RA Registry included information on 54,833 patients. Data on 419,183 patient visits and approximately 202,281 patient-years of follow-up observation time have been collected. The mean duration of patient follow-up is 4.5 years (median 3.2 years).

This study was carried out in accordance with the Declaration of Helsinki and all patients were required to provide written informed consent and authorization prior to participating. All participating investigators were required to obtain full Institutional Review Board (IRB) approval for conducting non-interventional research involving human subjects. Sponsor approval and continuing review was obtained through a central IRB (the New England Independent Review Board, NEIRB No. 120160610). For academic investigative sites that did not receive a waiver to use the central IRB, full approval was obtained from the respective governing IRBs and documentation was submitted to CorEvitas, LLC prior to initiating any study procedures.

\section{Study Population}

Adult patients (aged $\geq 18$ years) with RA, who were either treatment-naïve or -experienced, from the RA Registry who initiated treatment with abatacept, rituximab, tocilizumab, or tofacitinib were included. Eligible patients were 
required to have ACPA and CDAI measurements at or prior to the index date, and a follow-up visit 6 months after the index date. There was a 3-9-month window for the 6-month follow-up and the visit closest to 6 months was used if there was more than one visit. If patients initiated abatacept or another non-TNFi b/tsDMARD between study visits, CDAI measured within 4 months prior to initiation was used. Patients with abatacept use prior to the index date were excluded.

There was considerable variation in the duration of follow-up for the individual b/tsDMARDs, which reflects US Food and Drug Administration (FDA) approval dates for each drug. To allow for changes in clinical practice over time, patients were grouped by treatment initiation date. Different cohorts of patients who initiated treatment with abatacept, which was approved for use in 2005 [13], were evaluated based on the time of first approval of the other non-TNFi $b /$ tsDMARDs included in the study (rituximab, tocilizumab, or tofacitinib) (Fig. 1). These time periods were February 2006 to February 2019 for patients initiating abatacept or rituximab, February 2010 to February
2019 for patients initiating abatacept or tocilizumab, and December 2012 to February 2019 for patients initiating abatacept or tofacitinib. The index date was the date of initiation of abatacept or another non-TNFi b/tsDMARD.

\section{Study Assessments}

Patient characteristics at index were compared in each treatment initiation cohort by ACPA status in patients who initiated abatacept or another non-TNFi b/tsDMARD within a similar time period. ACPA+ status was defined as anticyclic citrullinated peptide-2 (anti-CCP2, a surrogate for ACPA) $\geq 20 \mathrm{U} / \mathrm{ml}$ and ACPA- status was defined as anti-CCP2 $<20 \mathrm{U} / \mathrm{ml}$.

The primary outcome was mean (standard deviation $[\mathrm{SD}]$ ) change in CDAI score from baseline to 6 months. Secondary outcomes included mean (SD) change in mHAQ score, and mean (SD) change in patient global assessment (PGA), patient-reported pain and fatigue scores, all measured by visual analog scale $(0-100 \mathrm{~mm})$ from baseline to 6 months. Additional assessments included the proportion of patients achieving CDAI-defined LDA (CDAI

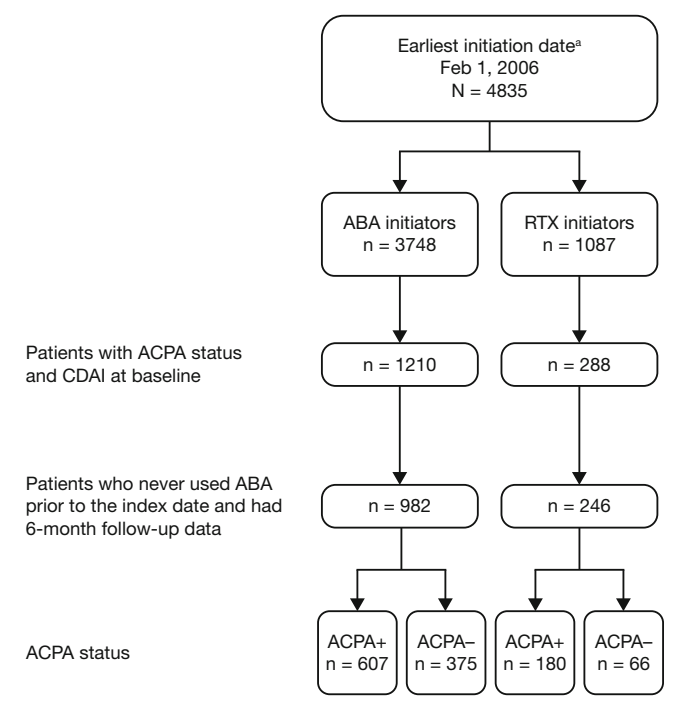

Fig. 1 Patient disposition. ${ }^{a}$ All dates ranged from the earliest initiation date to February 1, 2019. $A B A$ abatacept, $A C P A$ anti-citrullinated protein antibody, $C D A I$ Clinical Disease Activity Index, $R T X$ rituximab, $T C Z$ tocilizumab, $T O F A$ tofacitinib. Figure adapted from Harrold LR, et al.
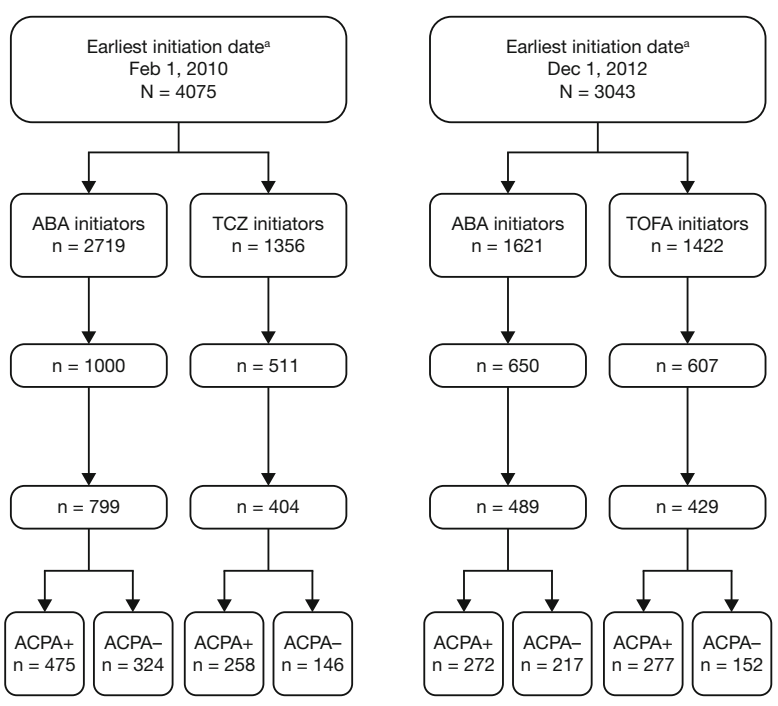

ACR/ARP Annual Meeting; November 8-13, 2019; abstract number: 1386. Reprinted from ACR Convergence held November 8-13, 2019. The American College of Rheumatology does not guarantee, warrant, or endorse any commercial products or services. Reprinted by Springer 
$\leq 10)$ or remission $(\mathrm{CDAI} \leq 2.8)$, and minimal clinically important difference (MCID) in CDAI score (a drop of $>1$ if LDA, $>6$ if moderate, or $>12$ if severe) at 6 months. Modified ACR (mACR) 20/50/70 response (20/50/70\% improvement in the number of tender and swollen joints and 20/50/70\% improvement in $>2$ of PGA, physician global assessment, patient pain and mHAQ scores; does not include erythrocyte sedimentation rate or C-reactive protein) at 6 months was also assessed.

\section{Statistical Analysis}

For patient characteristics, the ACPA+ and ACPA- groups for each drug were compared separately, using Student's $t$ tests for continuous variables and Chi-square and Fisher's exact tests for categorical variables. Clinical responses, by ACPA status, were estimated separately for abatacept and for specific non-TNFi b/tsDMARDs (rituximab, tocilizumab, or tofacitinib) within a similar time period of initiation (2006-2019, 2010-2019, or 2012-2019, respectively). Predicted mean differences between ACPA+ and ACPA-groups were estimated using mixed-effects linear regression models adjusting for baseline covariates (if $P<0.1$ ), with site as a random effect to adjust for potential site differences in treatment patterns. For binary outcomes, odds ratios were estimated using a mixed logistic regression model with the ACPA - group as a reference and site as a random effect, again, to adjust for potential site differences in treatment patterns. Outcomes were deemed statistically significant if $P<0.05$.

\section{RESULTS}

\section{Patient Disposition and Characteristics at Index}

Of the patients initiating treatment, there were 1228 patients in the abatacept/rituximab cohort (abatacept, $n=982$; rituximab, $n=246$ ), 1203 in the abatacept/tocilizumab cohort (abatacept, $n=799$; tocilizumab, $n=404$ ) and 918 in the abatacept/tofacitinib cohort (abatacept, $n=489$; tofacitinib, $n=429$ ) (Fig. 1). Overall, RA disease duration ranged from 8.8 to 12.6 years (Tables $1,2,3)$. Across treatments, patients who were ACPA+ had a longer duration of RA (range 10.6-12.6 years) than those who were ACPA- (range 8.8-10.3 years); mean differences in duration of RA were statistically significant for the three abatacept cohorts $(P=0.013, P=0.008$, and $P=0.022$, respectively) but not for the rituximab, tocilizumab, and tofacitinib cohorts (Tables 1, 2, 3).

A higher proportion of patients who were $\mathrm{ACPA}+$ had erosive disease (range 27.2-54.5\%) compared with those who were ACPA- (range 27.2-39.7\%) (Tables 1, 2, 3). A statistically significantly higher proportion of patients who were ACPA+ (range 78.6-83.6\%) were also $\mathrm{RF}+$ versus those who were ACPA-(range 33.7-50.0\%; $P<0.001$ ). A numerically higher proportion of patients who were ACPA+ were in the ACR functional class III/IV [14] at the index date $(P=0.039$ and $P=0.020$ for abatacept 2006-2019 and 2010-2019 cohorts, respectively, and $P=0.040$ for tocilizumab during 2010-2019).

The proportion of patients who received current therapy in combination with MTX and the proportion of patients with current prednisone use were similar across treatments and ACPA status. However, in the 2006-2019 cohort, statistically significantly more patients who were ACPA+, than those who were ACPA-, used prednisone $(P=0.006$ among abatacept initiators and $P=0.033$ among rituximab initiators).

\section{Mean Change from Baseline in Disease Activity and Disability Outcomes}

For patients who initiated abatacept in the 2006-2019 and 2010-2019 cohorts, the adjusted mean change in CDAI score at 6 months (primary outcome) following the index date was statistically significantly higher for patients who were ACPA+ versus those who were ACPA $-(P=0.033$ and $P<0.001$, respectively; Fig. 2A and B). In the 2012-2019 cohort, this difference was numerically higher but not 
Table 1 Baseline characteristics at index date for patients who initiated abatacept or rituximab during the 2006-2019 time period*

\begin{tabular}{|c|c|c|c|c|c|c|}
\hline & \multicolumn{3}{|l|}{ Abatacept } & \multicolumn{3}{|l|}{ Rituximab } \\
\hline & $\begin{array}{l}\text { ACPA- } \\
(n=375)\end{array}$ & $\begin{array}{l}\text { ACPA+ } \\
(n=607)\end{array}$ & $P$ & $\begin{array}{l}\text { ACPA- } \\
(n=66)\end{array}$ & $\begin{array}{l}\text { ACPA+ } \\
(n=180)\end{array}$ & $P$ \\
\hline Age, years & $58.8(13.6)$ & $58.6(12.9)$ & 0.818 & $58.9(12.3)$ & $59.1(13.1)$ & 0.925 \\
\hline Female, $n(\%)$ & $316(84.5)^{\mathrm{a}}$ & $484(79.7)$ & 0.062 & $53(80.3)$ & $139(77.2)$ & 0.605 \\
\hline Duration of RA, years & $9.0(9.1)$ & $10.6(10.2)$ & 0.013 & $10.3(10.2)$ & $12.6(10.4)$ & 0.127 \\
\hline $\mathrm{RF}+, n(\%)^{\mathrm{b}}$ & $119(35.4)$ & $445(83.3)$ & $<0.001$ & $29(50.0)$ & $126(80.8)$ & $<0.001$ \\
\hline Erosive disease, $n(\%)^{c}$ & $122(35.4)$ & $217(40.8)$ & 0.1070 & $23(39.7)$ & $85(54.5)$ & 0.054 \\
\hline ACR functional class III/IV, $n$ (\%) & $52(13.9)$ & $115(19.0)^{\mathrm{d}}$ & 0.039 & $11(16.7)$ & $40(22.2)$ & 0.341 \\
\hline \multicolumn{7}{|l|}{ History of comorbidities, $n$ (\%) } \\
\hline Diabetes & $41(10.9)$ & $64(10.5)$ & 0.848 & $7(10.6)$ & $20(11.1)$ & 0.911 \\
\hline Malignancies & $41(10.9)$ & $45(7.4)$ & 0.058 & $7(10.6)$ & $26(14.4)$ & 0.434 \\
\hline CVD & $47(12.5)$ & $81(13.3)$ & 0.714 & $9(13.6)$ & $28(15.6)$ & 0.709 \\
\hline \multicolumn{7}{|l|}{ Prior b/tsDMARDs, $n$ (\%) } \\
\hline 0 & $62(16.5)$ & $98(16.1)$ & 0.873 & $14(21.2)$ & $29(16.1)$ & 0.351 \\
\hline 1 & $121(32.3)$ & $198(32.6)$ & 0.909 & $25(37.9)$ & $72(40.0)$ & 0.763 \\
\hline$\geq 2$ & $192(51.2)$ & $311(51.2)$ & 0.991 & $27(40.9)$ & $79(43.9)$ & 0.676 \\
\hline CDAI score $(0-76)$ & $23.6(12.7)$ & $22.7(12.9)$ & 0.265 & $23.7(14.6)$ & $24.2(13.3)$ & 0.782 \\
\hline Patient global assessment, VAS $0-100 \mathrm{~mm}$ & $50.8(24.5)$ & $49.1(25.2)$ & 0.284 & $54.4(26.6)$ & $51.1(25.4)$ & 0.382 \\
\hline mHAQ score $(0-3)$ & $0.6(0.5)$ & $0.6(0.5)$ & 0.457 & $0.6(0.6)$ & $0.7(0.6)$ & 0.600 \\
\hline Patient pain, VAS $0-100 \mathrm{~mm}$ & $53.6(26.1)$ & $52.1(27.0)$ & 0.390 & $53.3(26.0)$ & $50.5(27.2)$ & 0.480 \\
\hline Patient fatigue, VAS $0-100 \mathrm{~mm}$ & $55.3(27.6)$ & $52.8(29.0)$ & 0.233 & $55.8(31.5)$ & $52.4(28.2)$ & 0.513 \\
\hline \multicolumn{7}{|l|}{ Current therapy, $n$ (\%) } \\
\hline Monotherapy & $103(27.5)$ & $166(27.3)$ & 0.968 & $9(13.6)$ & $35(19.4)$ & 0.292 \\
\hline Combination therapy with MTX only & $143(38.1)$ & $268(44.2)$ & 0.063 & $29(43.9)$ & $90(50.0)$ & 0.399 \\
\hline Current prednisone use, $n(\%)$ & $115(30.7)$ & $239(39.4)$ & 0.006 & $17(25.8)$ & $73(40.6)$ & 0.033 \\
\hline
\end{tabular}

Data are mean (SD) unless stated otherwise. *Patients who initiated abatacept or rituximab from February 1, 2006 to February 28,2019 ${ }^{\mathrm{a}} n=374$

${ }^{\mathrm{b}} \mathrm{RF}$ and ACPA testing are not required for all patients in the RA Registry; therefore, these counts are only available for a reduced number of patients; abatacept $n=336$ and 534, rituximab $n=58$ and 156, for ACPA- and ACPA+, respectively

${ }^{\mathrm{c}}$ Abatacept $n=345$ and 532, rituximab $n=58$ and 156, for ACPA- and ACPA+, respectively

$\mathrm{d}_{n}=606$

$A C R$ American College of Rheumatology, $A C P A+$ anti-citrullinated protein antibody positive (anti-CCP2 $\geq 20 \mathrm{U} / \mathrm{ml}$ ), $A C P A-$ anti-citrullinated protein antibody negative (anti-CCP2 $<20 \mathrm{U} / \mathrm{ml}$ ), anti-CCP2 anti-cyclic citrullinated peptide-2, b/tsDMARD biologic or targeted-synthetic disease-modifying antirheumatic drug, CDAI Clinical Disease Activity Index, CVD cardiovascular disease, $m H A Q$ modified Health Assessment Questionnaire, $M T X$ methotrexate, $R A$ rheumatoid arthritis, $R F+$ rheumatoid factor positive, $S D$ standard deviation, $V A S$ visual analog scale Table adapted from Harrold LR, et al. ACR/ARP Annual Meeting; November 8-13, 2019; abstract number: 1386. Reprinted from ACR Convergence held November 8-13, 2019. The American College of Rheumatology does not guarantee, warrant, or endorse any commercial products or services. Reprinted by Springer 
Table 2 Baseline characteristics at index date for patients who initiated abatacept or tocilizumab during the 2010-2019 time period*

\begin{tabular}{|c|c|c|c|c|c|c|}
\hline & \multicolumn{3}{|l|}{ Abatacept } & \multicolumn{3}{|c|}{ Tocilizumab } \\
\hline & $\begin{array}{l}\text { ACPA- } \\
(n=324)\end{array}$ & $\begin{array}{l}\text { ACPA+ } \\
(n=475)\end{array}$ & $P$ & $\begin{array}{l}\text { ACPA- } \\
(n=146)\end{array}$ & $\begin{array}{l}\text { ACPA+ } \\
(n=258)\end{array}$ & $P$ \\
\hline Age, years & $59.4(13.6)$ & $59.1(12.6)$ & 0.745 & $57.0(13.8)$ & $55.9(12.7)$ & 0.414 \\
\hline Female, $n(\%)$ & $272(84.2)^{\mathrm{a}}$ & $378(79.6)$ & 0.098 & $106(72.6)$ & $204(79.1)$ & 0.139 \\
\hline Duration of RA, years & $8.8(9.0)$ & $10.6(9.8)$ & 0.008 & $9.2(8.8)$ & $11.1(9.9)$ & 0.054 \\
\hline $\mathrm{RF}+, n(\%)^{\mathrm{b}}$ & $102(34.7)$ & $346(83.6)$ & $<0.001$ & $53(40.2)$ & $180(78.6)$ & $<0.001$ \\
\hline Erosive disease, $n(\%)^{c}$ & $109(36.1)$ & $168(39.8)$ & 0.310 & $53(38.7)$ & $85(35.7)$ & 0.566 \\
\hline ACR functional class III/IV, $n(\%)$ & $46(14.2)$ & $98(20.6)$ & 0.020 & $21(14.4)$ & $59(22.9)$ & 0.040 \\
\hline \multicolumn{7}{|l|}{ History of comorbidities, $n$ (\%) } \\
\hline Diabetes & $37(11.4)$ & $50(10.5)$ & 0.691 & $11(7.5)$ & $25(9.7)$ & 0.465 \\
\hline Malignancies & $38(11.7)$ & $38(8.0)$ & 0.078 & $9(6.2)$ & $11(4.3)$ & 0.397 \\
\hline CVD & $46(14.2)$ & $65(13.7)$ & 0.837 & $25(17.1)$ & $26(10.1)$ & 0.041 \\
\hline \multicolumn{7}{|l|}{ Prior b/tsDMARDs, $n(\%)$} \\
\hline 0 & $57(17.6)$ & $80(16.8)$ & 0.782 & $12(8.2)$ & $24(9.3)$ & 0.714 \\
\hline 1 & $93(28.7)$ & $152(32.0)$ & 0.321 & $56(38.4)$ & $96(37.2)$ & 0.819 \\
\hline$\geq 2$ & $174(53.7)$ & $243(51.2)$ & 0.479 & $78(53.4)$ & $138(53.5)$ & 0.990 \\
\hline CDAI score $(0-76)$ & $24.0(12.5)$ & $22.3(13.0)$ & 0.065 & $25.3(14.2)$ & $22.2(14.3)$ & 0.037 \\
\hline Patient global assessment, VAS $0-100 \mathrm{~mm}$ & $51.9(24.5)$ & $48.7(25.5)$ & 0.076 & $53.9(23.4)$ & $50.9(26.9)$ & 0.251 \\
\hline mHAQ score $(0-3)$ & $0.6(0.5)$ & $0.6(0.5)$ & 0.821 & $0.7(0.5)$ & $0.7(0.6)$ & 0.996 \\
\hline Patient pain, VAS $0-100 \mathrm{~mm}$ & $54.6(26.1)$ & $51.8(27.2)$ & 0.148 & $55.8(26.5)$ & $52.7(28.3)$ & 0.292 \\
\hline Patient fatigue, VAS 0-100 mm & $55.3(27.6)$ & $52.8(29.0)$ & 0.233 & $54.9(29.0)$ & $55.3(29.0)$ & 0.893 \\
\hline \multicolumn{7}{|l|}{ Current therapy, $n(\%)$} \\
\hline Monotherapy & $91(28.1)$ & $142(29.9)$ & 0.581 & $47(32.2)$ & $68(26.4)$ & 0.212 \\
\hline Combination therapy with MTX only & $117(36.1)$ & $191(40.2)$ & 0.242 & $60(41.1)$ & $119(46.1)$ & 0.328 \\
\hline Current prednisone use, $n(\%)$ & $102(31.5)$ & $175(36.8)$ & 0.118 & $42(28.8)$ & $89(34.5)$ & 0.237 \\
\hline
\end{tabular}

Data are mean (SD) unless stated otherwise. ${ }^{*}$ Patients who initiated abatacept or tocilizumab from February 1, 2010 to February 28,2019 ${ }^{\mathrm{a}} n=323$

${ }^{\mathrm{b}} \mathrm{RF}$ and ACPA testing are not required for all patients in the RA Registry; therefore, these counts are only available for a reduced number of patients; abatacept $n=294$ and 414, tocilizumab $n=132$ and 229, for ACPA- and ACPA+, respectively

cAbatacept $n=302$ and 422, tocilizumab $n=137$ and 238, for ACPA- and ACPA + , respectively

$A C R$ American College of Rheumatology, $A C P A+$ anti-citrullinated protein antibody positive (anti-CCP2 $\geq 20 \mathrm{U} / \mathrm{ml}$ ), $A C P A-$ anti-citrullinated protein antibody negative (anti-CCP2 $<20 \mathrm{U} / \mathrm{ml}$ ), anti-CCP2 anti-cyclic citrullinated peptide-2, b/tsDMARD biologic or targetedsynthetic disease-modifying antirheumatic drug, CDAI Clinical Disease Activity Index, $C V D$ cardiovascular disease, $m H A Q$ modified Health Assessment Questionnaire, $M T X$ methotrexate, $R A$ rheumatoid arthritis, $R F+$ rheumatoid factor positive, $S D$ standard deviation, $V A S$ visual analog scale

Table adapted from Harrold LR, et al. ACR/ARP Annual Meeting; November 8-13, 2019; abstract number: 1386. Reprinted from ACR Convergence held November 8-13, 2019. The American College of Rheumatology does not guarantee, warrant, or endorse any commercial products or services. Reprinted by Springer 
Table 3 Baseline characteristics at index date for patients who initiated abatacept or tofacitinib during the 2012-2019 time period*

\begin{tabular}{|c|c|c|c|c|c|c|}
\hline & \multicolumn{3}{|l|}{ Abatacept } & \multicolumn{3}{|l|}{ Tofacitinib } \\
\hline & $\begin{array}{l}\text { ACPA- } \\
(n=217)\end{array}$ & $\begin{array}{l}\text { ACPA+ } \\
(n=272)\end{array}$ & $P$ & $\begin{array}{l}\text { ACPA- } \\
(n=152)\end{array}$ & $\begin{array}{l}\text { ACPA+ } \\
(n=277)\end{array}$ & $P$ \\
\hline Age, years & $60.3(13.7)$ & $60.8(12.6)$ & 0.720 & $59.3(12.5)$ & $59.4(11.7)$ & 0.927 \\
\hline Female, $n(\%)$ & $184(84.8)$ & $217(79.8)$ & 0.152 & $121(79.6)$ & $209(75.5)$ & 0.361 \\
\hline Duration of RA, years & $9.4(9.4)$ & $11.6(11.0)$ & 0.022 & $9.5(9.0)$ & $11.4(9.7)$ & 0.056 \\
\hline $\mathrm{RF}+, n(\%)^{\mathrm{a}}$ & $66(33.7)$ & $201(82.7)$ & $<0.001$ & $53(38.1)$ & $208(82.2)$ & $<0.001$ \\
\hline Erosive disease, $n(\%)^{\mathrm{b}}$ & $65(30.7)$ & $87(33.5)$ & 0.517 & $41(27.2)$ & $75(27.2)$ & 0.996 \\
\hline ACR functional class III/IV, $n$ (\%) & $29(13.4)$ & $49(18.0)$ & 0.163 & $20(13.2)$ & $49(17.7)$ & 0.222 \\
\hline \multicolumn{7}{|l|}{ History of comorbidities, $n$ (\%) } \\
\hline Diabetes & $21(9.7)$ & $28(10.3)$ & 0.821 & $17(11.2)$ & $33(11.9)$ & 0.822 \\
\hline Malignancies & $23(10.6)$ & $28(10.3)$ & 0.913 & $15(9.9)$ & $18(6.5)$ & 0.210 \\
\hline CVD & $34(15.7)$ & $40(14.7)$ & 0.768 & $14(9.2)$ & $48(17.3)$ & 0.022 \\
\hline \multicolumn{7}{|l|}{ Prior b/tsDMARDs, $n(\%)$} \\
\hline 0 & $40(18.4)$ & $46(16.9)$ & 0.661 & $39(25.7)$ & $65(23.5)$ & 0.612 \\
\hline 1 & $61(28.1)$ & $69(25.4)$ & 0.495 & $42(27.6)$ & $87(31.4)$ & 0.415 \\
\hline$\geq 2$ & $116(53.5)$ & $157(57.7)$ & 0.345 & $71(46.7)$ & $125(45.1)$ & 0.753 \\
\hline CDAI score $(0-76)$ & $23.2(12.1)$ & $21.0(12.6)$ & 0.049 & $21.8(13.9)$ & $19.9(12.5)$ & 0.159 \\
\hline Patient global assessment, VAS $0-100 \mathrm{~mm}$ & $50.5(24.4)$ & $48.2(25.6)$ & 0.308 & $52.7(25.5)$ & $48.2(26.3)$ & 0.082 \\
\hline mHAQ score $(0-3)$ & $0.6(0.5)$ & $0.6(0.6)$ & 0.788 & $0.6(0.5)$ & $0.6(0.5)$ & 0.448 \\
\hline Patient pain, VAS $0-100 \mathrm{~mm}$ & $54.1(26.2)$ & $52.0(28.0)$ & 0.404 & $56.9(26.7)$ & $50.9(27.6)$ & 0.029 \\
\hline Patient fatigue, VAS $0-100 \mathrm{~mm}$ & $55.6(27.2)$ & $51.5(29.5)$ & 0.109 & $54.3(29.4)$ & $50.4(30.3)$ & 0.201 \\
\hline \multicolumn{7}{|l|}{ Current therapy, $n(\%)$} \\
\hline Monotherapy & $63(29.0)$ & $86(31.6)$ & 0.537 & $72(47.4)$ & $102(36.8)$ & 0.033 \\
\hline Combination therapy with MTX only & $72(33.2)$ & $91(33.5)$ & 0.949 & $43(28.3)$ & $94(33.9)$ & 0.230 \\
\hline Current prednisone use, $n(\%)$ & $67(30.9)$ & $97(35.7)$ & 0.265 & $39(25.7)$ & $88(31.8)$ & 0.185 \\
\hline
\end{tabular}

Data are mean (SD) unless stated otherwise. *Patients who initiated abatacept or tofacitinib from December 1, 2012 to February 28,2019 ${ }^{a} \mathrm{RF}$ and ACPA testing are not required for all patients in the RA Registry; therefore, these counts are only available for a reduced number of patients; abatacept $n=196$ and 243, tofacitinib $n=139$ and 253, for ACPA- and ACPA+, respectively

bAbatacept $n=212$ and 260, tofacitinib $n=151$ and 276, for ACPA- and ACPA+, respectively

$A C R$ American College of Rheumatology, $A C P A+$ anti-citrullinated protein antibody-positive (anti-CCP2 $\geq 20 \mathrm{U} / \mathrm{ml}$ ), $A C P A-$ anticitrullinated protein antibody negative (anti-CCP2 $<20 \mathrm{U} / \mathrm{ml}$ ), anti-CCP2 anti-cyclic citrullinated peptide-2, b/tsDMARD biologic or targeted-synthetic disease-modifying antirheumatic drug, $C D A I$ Clinical Disease Activity Index, $C V D$ cardiovascular disease, $m H A Q$ modified Health Assessment Questionnaire, $M T X$ methotrexate, $R A$ rheumatoid arthritis, $R F+$ rheumatoid factor positive, $S D$ standard deviation, $V A S$ visual analog scale

Table adapted from Harrold LR, et al. ACR/ARP Annual Meeting; November 8-13, 2019; abstract number: 1386. Reprinted from ACR Convergence held November 8-13, 2019. The American College of Rheumatology does not guarantee, warrant, or endorse any commercial products or services. Reprinted by Springer 

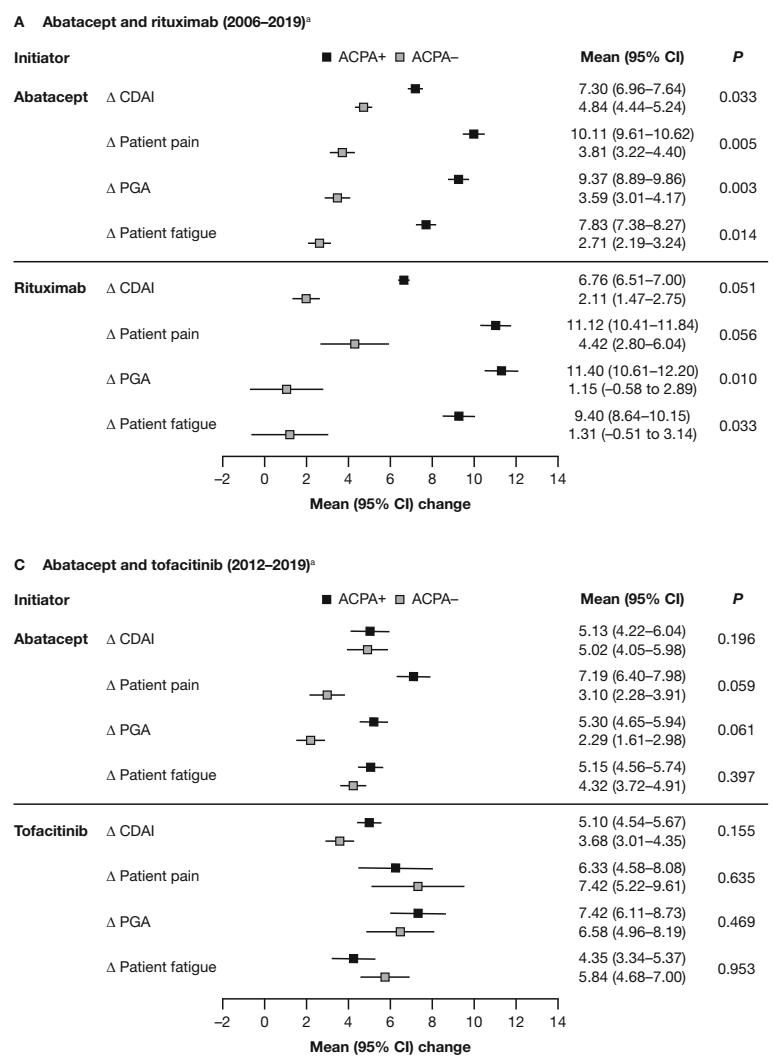

Fig. 2 Adjusted mean improvement from baseline in disease and disability outcomes at 6 months after index date, by ACPA status, for patients who initiated abatacept or another non-TNFi b/tsDMARD.* A Abatacept and rituximab (2006-2019) ${ }^{a}$. B Abatacept and tocilizumab (2010-2019) $)^{a}$. C Abatacept and tofacitinib (2012-2019) ${ }^{a}$. *Adjusted for baseline covariates that differed by ACPA status $(P<0.1)$, not including factors that reduced the sample size by $>10 \%$ or were correlated with CDAI. Only the main variable category is listed below, although some variables were further broken down within each category: Adjusted variables for the 2006-2019 cohort included: for both drugs - BMI, marital status, smoking status, and prednisone use; for abatacept only - sex, race/ethnicity, insurance, college, work status, duration of RA, ACR functional class, history of malignancies, history of hypertension, history of serious infection, and current combination therapy; and for rituximab only - history of COPD. Adjusted variables for the 2010-2019 cohort included: for both drugs - race/ethnicity, insurance, work status, duration of RA, ACR functional class, and CDAI; for abatacept only - sex, marital status, smoking status, history of malignancies, history of hypertension, history of

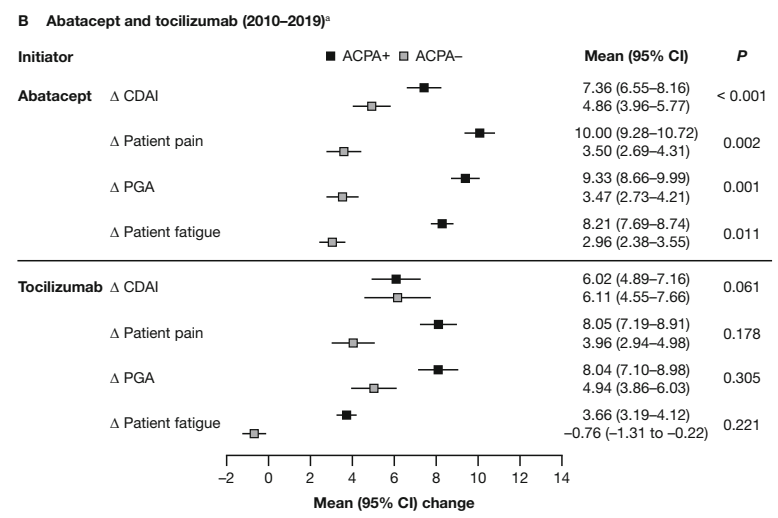

serious infections, current combination therapy, morning stiffness, and initiation year; and for tocilizumab only age, history of CVD, and prednisone use. Adjusted variables for the 2012-2019 cohort included: for both drugs - college, duration of RA, and CDAI; for abatacept only - race/ethnicity, BMI, marital status, work status, and initiation year; for tofacitinib only - history of CVD, history of serious infections, prior non-TNFi use, current combination therapy, and patient pain. ${ }^{a}$ Time period of initiation; refer to the Methods section for full details. $\triangle$ change, ACR American College of Rheumatology, $A C P A+$ anti-citrullinated protein antibody positive (anti-CCP2 $\geq 20 \mathrm{U} / \mathrm{ml}$ ), $A C P A-$ anti-citrullinated protein antibody negative (anti-CCP $2<20 \mathrm{U} / \mathrm{ml}$ ), antiCCP2 anti-cyclic citrullinated peptide-2, b/tsDMARD biologic or targeted-synthetic disease-modifying antirheumatic drug, $B M I$ body mass index, $C D A I$ Clinical Disease Activity Index, $C I$ confidence interval, $C O P D$ chronic obstructive pulmonary disease, csDMARD conventionalsynthetic disease-modifying antirheumatic drug, $C V D$ cardiovascular disease, $P G A$ patient global assessment, $R A$ rheumatoid arthritis, $T N F i$ tumor necrosis factor inhibitor 

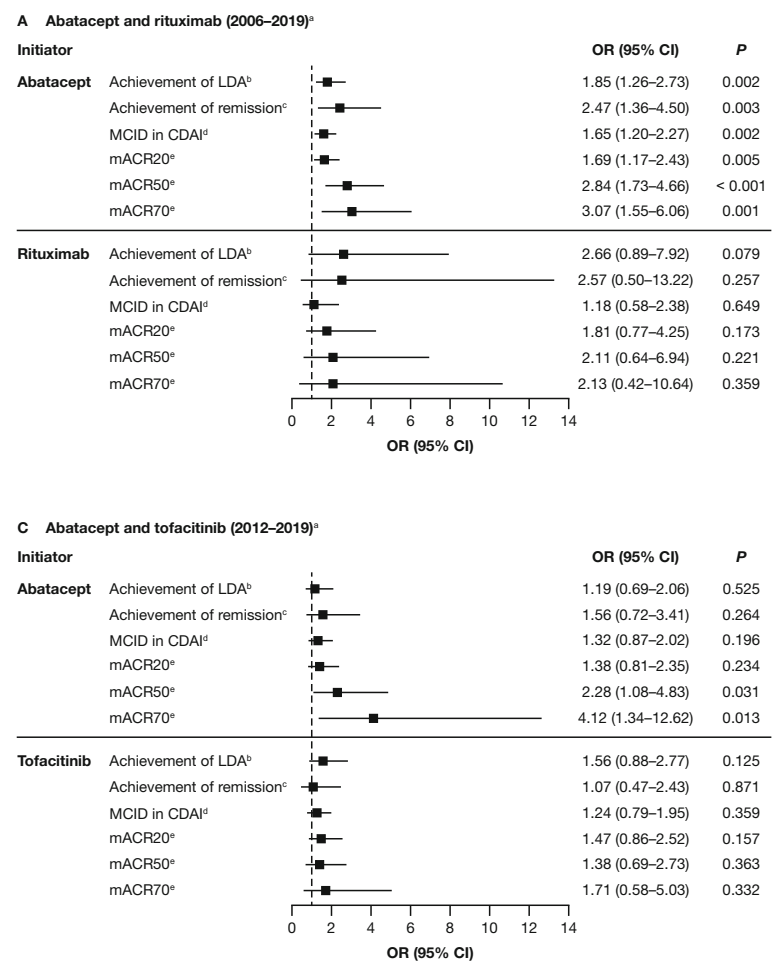

Fig. 3 Adjusted association between ACPA status and achieving a clinical response to treatment with abatacept or another non-TNFi b/tsDMARD at 6 months after index date. ${ }^{*}$ A Abatacept and rituximab (2006-2019)a. B Abatacept and tocilizumab (2010-2019) ${ }^{\text {. }}$. C Abatacept and tofacitinib (2012-2019) $)^{\mathrm{a}}$. Data are presented as odds ratio (95\% CI). *Adjusted for baseline covariates that differed by baseline CCP status $(P<0.1)$, not including factors that reduced the sample size by $>10 \%$ or were correlated with CDAI: adjusted variables for each cohort are listed in the footnote of Fig. 2. ${ }^{\text {a }}$ Time period of initiation; refer to the Methods section for full details. ${ }^{\mathrm{b}} \mathrm{CDAI} \leq 10$ (among those with moderate or higher disease activity). ${ }^{\circ} \mathrm{CDAI} \leq 2.8$ (among those with LDA or higher). ${ }^{\mathrm{d}}$ Drop of $>1$ if LDA, drop of $>6$ if moderate disease activity, and drop of $>12$ if severe disease activity.

statistically significant (Fig. 2C). Similarly, mean changes in mHAQ, PGA, and patient-reported pain and fatigue scores at 6 months following the index date were statistically significantly higher for patients who were ACPA+ and who initiated abatacept during 2006-2019 and 2010-2019 versus patients who were ACPA- $(P<0.05$; Fig. 2A \& B and Fig. S1A $\&$ S1B [Supplementary Material]).

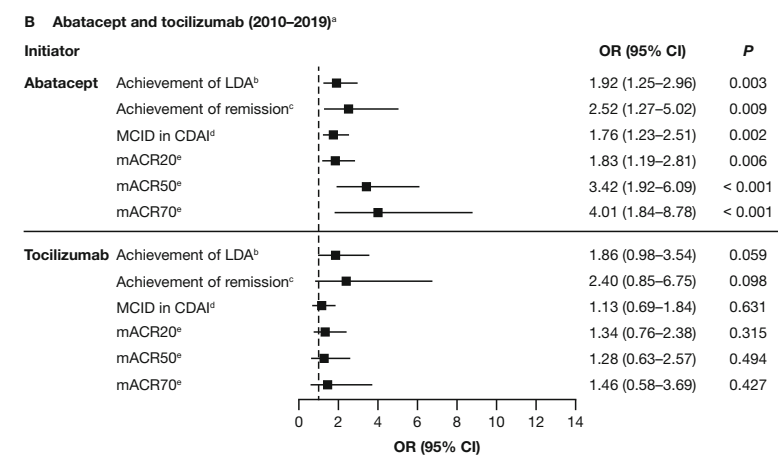

${ }^{e} \mathrm{mACR}$ criteria based on two out of four measures (not using ESR or CRP). ACPA anti-citrullinated protein antibody, $C C P$ cyclic citrullinated peptide, $C D A I$ Clinical Disease Activity Index, $C I$ confidence interval, $C R P$ C-reactive protein, ESR erythrocyte sedimentation rate, $L D A$ low disease activity, mACR20/50/70 20/50/70\% improvement in modified American College of Rheumatology criteria, $M C I D$ minimal clinically important difference, $O R$ odds ratio, $T N F i$ tumor necrosis factor inhibitor. Figure adapted from Harrold LR, et al. ACR/ARP Annual Meeting; November 8-13, 2019; abstract number: 1386. Reprinted from ACR Convergence held November 8-13, 2019. The American College of Rheumatology does not guarantee, warrant, or endorse any commercial products or services. Reprinted by Springer

For patients who initiated rituximab, only the adjusted mean change in PGA and patient-reported fatigue scores were statistically significantly higher among patients who were ACPA+ versus ACPA $-(P=0.010$ and $P=0.033$, respectively); differences in other secondary outcomes were not statistically significant (Fig. 2A and Fig. S1A).

There were no statistically significant differences in adjusted mean change in CDAI score or 
secondary outcomes by ACPA status observed in patients who initiated either tocilizumab or tofacitinib (Fig. 2B and C and Fig. S1B and S1C).

\section{Association Between ACPA Status and Clinical Outcomes}

There was a statistically significant association between ACPA status and the achievement of CDAI-defined LDA and remission, MCID in CDAI score, and mACR20/50/70 responses in the 2006-2019 (Fig. 3A) and 2010-2019 (Fig. 3B) cohorts for patients who initiated abatacept. With the exception of mACR50 and mACR70, these associations were not statistically significant in 2012-2019 (Fig. 3C).

No statistically significant differences in CDAI-defined LDA or remission, MCID in CDAI score, or mACR20/50/70 responses by ACPA status were observed for patients who initiated rituximab, tocilizumab or tofacitinib (Fig. 3A-C).

\section{DISCUSSION}

This real-world study of adults with ACPA+ RA who initiated abatacept or another non-TNFi $\mathrm{b} /$ tsDMARD provides valuable insight into the effect of ACPA status on clinical outcomes and response to treatment. Across treatments and time periods, at index date, ACPA positivity was associated with worse clinical characteristics. Among patients initiating abatacept, improvements in most treatment outcomes were statistically significantly better for those who were ACPA+ versus ACPA-. For non-TNFi b/tsDMARDs other than abatacept, statistically significant differences in treatment outcomes at 6 months (PGA and patient-reported fatigue) by baseline ACPA status were only observed for patients initiating treatment with rituximab, not tocilizumab or tofacitinib. These results highlight the heterogeneous nature of RA indeed it is now thought that seropositive and seronegative RA represent distinct disease entities [15] - and suggest that a patient's response to different treatments with different mechanisms of action (MOA) may vary depending on their underlying serology.
At index in this study, patients with ACPA+ RA had a longer duration and more severe course of disease, as measured by erosive changes, and were more likely to be in the highest ACR functional class (III/IV), irrespective of treatment. These data are aligned with previous studies that show a correlation between ACPA positivity and a more severe, erosive disease course $[2,3,16,17]$. A study of 454 patients with RA showed that patients with $\mathrm{ACPA}+\mathrm{RA}$ had more severe radiographic joint destruction over 4 years than patients with ACPA - RA [2]. Patients included in our analysis were more likely to be $\mathrm{RF}+$ if they were ACPA+ compared with ACPA-. This is a critical characteristic of patients with seropositive RA: studies have shown the additive effect of ACPA, $\mathrm{RF}$, and other autoantibody positivity may lead to a more severe RA disease course [3, 17-19].

In the present study, patients with ACPA+ RA treated with abatacept had a good response to treatment, as shown by statistically significant changes in clinical outcomes from index date to 6 months and an association with achieving a clinical response compared with patients with ACPA-RA. This is consistent with previous findings from randomized clinical studies $[7,8]$, real-world observational studies $[9,12]$, and a collaborative registry analysis [11]. In the AMPLE study, patients with $\mathrm{ACPA}+\mathrm{RA}$ had better clinical responses to abatacept or abatacept + MTX, than patients with ACPA- RA [7]. A post hoc analysis of the AVERT study in patients with ACPA IgG+ RA, combination abatacept + MTX therapy showed greater clinical efficacy in patients who were also ACPA IgM+ versus ACPA IgM - at baseline [8]. The presence of ACPA IgM may indicate an ongoing immune response that involves the recruitment of naïve B cells [20]. Previous analyses from CorEvitas' RA Registry and a collaboration of 16 European registries have demonstrated an association between ACPA status and response to treatment with abatacept $[9,11,12]$. In the current study, trends were generally consistent across most time periods. Among patients treated with abatacept in 2012-2019, a statistically significant difference between patients with ACPA+ and ACPA- RA was observed only for the odds of achieving 
mACR50 and mACR70 response. The sample size for this later cohort was smaller than the earlier 2006-2019 and 2010-2019 cohorts (which may have impacted statistical power), baseline disease activity was lower and disease duration was longer compared with the 2006-2019 cohort, therefore smaller changes in disease activity and clinical responses may be expected.

Differences in response to treatment with abatacept between patients who were ACPA+ and ACPA-, in contrast to those observed with TNFi or other non-TNFi b/tsDMARDs, may be related to differences in MOA [21]. Abatacept blocks CD80/86-CD28 co-stimulation of antigen presenting cells and $\mathrm{T}$ cells, inhibiting downstream B-cell activity and autoantibody production, while rituximab, a B-cell-specific anti-CD20 antibody, acts as a B-cell depleting agent [21]. Through B-cell modification, both agents effectively reduce levels of antibodies, potentially explaining their relative effectiveness in patients with seropositive compared with seronegative RA. However, while agents such as tocilizumab or tofacitinib that inhibit interleukin-6 (IL-6) signaling have some impact on T- and B-cell responses, IL-6 also regulates other broader proinflammatory pathways involved in autoimmune disorders such as RA [22].

Here we report a higher proportion of patients with ACPA+ RA treated with rituximab had statistically significant changes 6 months after index date in PGA and patient-reported fatigue scores than patients who were ACPA-. Interestingly, there were no statistically significant changes in disease and patient-reported outcomes or the achievement of treatment response for patients with ACPA+ RA treated with tocilizumab or tofacitinib, compared with patients with ACPA- RA. While previous studies have shown little difference in treatment response to TNFis in patients who are ACPA+ versus ACPA- $[9,12,23]$, data on the clinical effectiveness and treatment response of non-TNFi b/tsDMARDs in patients with ACPA+ and ACPA - RA are lacking. Two small analyses ( $n=25$ and $n=30)$ that investigated response to rituximab treatment provided contradictory results [24, 25]; one concluded that patients with a good response to rituximab had lower baseline ACPA IgM than patients with moderate/no response [24] and the other found clinical response was better in patients where antibody levels (including ACPA) were higher (versus lower) at baseline [25].

Similar to the results we report here, analysis of 316 patients with RA from CorEvitas' RA Registry concluded that response to tocilizumab did not differ by ACPA status [16]. A collaboration of 16 European RA registries $(n=27,583)$ found seropositivity (RF+ and/or ACPA+) was associated with longer drug maintenance and higher response rates for abatacept, rituximab, and tocilizumab, but not TNFis [11]. This difference in overall drug retention between seropositive versus seronegative patients was statistically significant for patients treated with abatacept and rituximab, but not tocilizumab. Thus, similar to our study, this large collaborative analysis found that the effect of seropositivity was greater for abatacept and rituximab, than tocilizumab.

Outcomes for patients with seronegative and seropositive RA treated with tofacitinib were assessed in a post hoc pooled analysis of five phase III randomized clinical trials $(n=3061)$ and a pooled analysis of long-term extension studies $(n=4967)[26,27]$. In contrast to the current study, patients who were ACPA+ / $\mathrm{RF}+$ were more likely to achieve a response with tofacitinib than patients who were ACPA- / $\mathrm{RF}-$; those who were ACPA+ were more likely to achieve remission or LDA in Disease Activity Score in 28 joints with erythrocyte sedimentation rate than patients who were ACPA- / RF- [26]. The contrasting outcomes observed for different non-TNFi b/tsDMARDs between previous studies and the present analysis may be partially explained by heterogeneity in data sources, study design, sample size, and data analysis, e.g., for the present analysis, treatment response was not stratified by baseline RF status.

This study has several strengths. The RA Registry is a US-based registry that includes a large number of patients with RA with physician-validated outcome measures and is representative of patients found in clinical practice in the US [28]. Previous analyses have compared Medicare patients with RA enrolled in the RA 
Registry to those not enrolled and found similar demographic and comorbidity characteristics, supporting the generalizability of data from the registry [28]. Several different treatments were analyzed in this study: outcomes by ACPA status were assessed among patients treated with abatacept, the non-TNFi bDMARDs rituximab and tocilizumab, and the tsDMARD tofacitinib. Results from this study support data from previously reported analyses that show patients with ACPA+ RA experience a more severe disease course and are more likely to experience a better response to treatment, than patients with ACPA- RA [2, 3, 7-9, 11, 12, 17].

One limitation was the relatively small sample size, particularly for rituximab-treated patients, and the relatively short duration of follow-up (6 months) for all treatments. There was considerable variation in the timing of follow-up for patients treated with the individual treatments. To overcome this, and to allow for changes in clinical practice over time, patients were grouped based on the availability of rituximab, tocilizumab, or tofacitinib, which reflected the FDA approval date for each drug. It should be noted that the study was not designed to compare differences in outcomes between abatacept and other b/tsDMARDs. At the time of collection of the present data only one Janus kinase (JAK) inhibitor (tofacitinib) [29] and one IL-6 inhibitor (tocilizumab) [30] were FDA approved; consequently patients treated with other JAK or IL-6 inhibitors were not included. Additionally, selection bias should be considered as a limitation due to prescribing patterns potentially being influenced by serological status - the impact of serological status in the efficacy of some bDMARDs has gained increasing evidence [31-34]; as such, selection bias may have increased during the study period. As with all real-world studies, patients enrolled in the registry may not fully reflect patients with RA observed in other regions or areas of general practice.

\section{CONCLUSIONS}

In conclusion, after 6 months of therapy, the improvement in outcomes among patients with $\mathrm{ACPA}+\mathrm{RA}$ treated with abatacept or rituximab was statistically significantly better than outcomes among the respective patients with ACPA- RA. By contrast, no statistically significant difference in clinical response was observed between patients with ACPA+ and ACPA- RA treated with tocilizumab or tofacitinib. The data presented here demonstrate that patients with RA may respond differently to treatments with different MOA based on their underlying serology. More research is needed to fully elucidate the cause-and-effect relationship between serology and response to treatment in patients with RA, to help clinicians plan treatment on a patient-by-patient basis. An analysis comparing the effectiveness of abatacept versus other non-TNFi b/tsDMARDs by ACPA status is planned.

\section{ACKNOWLEDGEMENTS}

The authors would like to thank all of the participating providers and patients for contributing data to this study.

Funding. The Rapid Service Fee was funded by Bristol Myers Squibb. This study was sponsored by CorEvitas, LLC and the analysis was funded by Bristol Myers Squibb. Access to study data was limited to CorEvitas, LLC and CorEvitas, LLC statisticians completed all of the analysis; all authors contributed to the interpretation of the results. CorEvitas, LLC has been supported through contracted subscriptions in the last 2 years by AbbVie, Amgen, Boehringer Ingelheim, Bristol Myers Squibb, Celgene, Chugai, Eli Lilly, Genentech, Gilead, Janssen, Novartis, Ortho Dermatologics, Pfizer, Regeneron, Sanofi, Sun Pharma, and UCB. Professional medical writing and editorial assistance was funded by Bristol Myers Squibb.

Medical Writing and Editorial Assistance. Professional medical writing and 
editorial assistance was provided by Rachel Rankin, PhD at Caudex and was funded by Bristol Myers Squibb.

Authorship. All named authors meet the International Committee of Medical Journal Editors (ICMJE) criteria for authorship for this article, take responsibility for the integrity of the work as a whole, and have given their approval for this version to be published.

Author Contributions. Access to study data was limited to CorEvitas and CorEvitas statisticians completed all of the analysis; all authors contributed to the interpretation of the results, and drafting and review of the manuscript.

Prior Presentation. These data were previously presented at ACR 2019 (Harrold L, Shan Y, Rebello S, et al. November 8-13, 2019, poster 1386), Congress of Clinical Rheumatology (CCR)-East 2020 (Harrold LR, Shan Y, Rebello S, et al. September 10-13, 2020 [virtual meeting]) and Kongress der Deutschen Gesellschaft für Rheumatologie (DGRh) 2020 (Harrold LR, Shan Y, Rebello S, et al. September 9-12, 2020, poster RA.13 [virtual meeting]). The posters were a collaborative effort between CorEvitas, LLC and Bristol Myers Squibb, with financial support provided by Bristol Myers Squibb.

Disclosures. Leslie R. Harrold is an employee and shareholder of CorEvitas, LLC; received grant/research support from Pfizer; consulting fees from AbbVie, Bristol Myers Squibb, and Roche; and speaker's bureau for Bristol Myers Squibb. Ying Shan, Sabrina Rebello*, and Lin Guo are employees of CorEvitas, LLC. Sean E. Connolly, Keith Wittstock, Joe Zhuo, Sheila Kelly, Thomas Lehman and Vadim Khaychuk are employees and shareholders of Bristol Myers Squibb. *At the time of analysis; current affiliation: Amyloidosis Research Consortium, 320 Nevada Street, Suite 210, Newton, MA, USA.

Compliance with Ethics Guidelines. This study was carried out in accordance with the Declaration of Helsinki and all patients were required to provide written informed consent and authorization prior to participating. All participating investigators were required to obtain full Institutional Review Board (IRB) approval for conducting non-interventional research involving human subjects. Sponsor approval and continuing review was obtained through a central IRB (the New England Independent Review Board, NEIRB No. 120160610). For academic investigative sites that did not receive a waiver to use the central IRB, full approval was obtained from the respective governing IRBs and documentation was submitted to CorEvitas, LLC prior to initiating any study procedures.

Data Availability. Bristol Myers Squibb's policy on data sharing may be found at https:// www.bms.com/researchers-and-partners/ independent-research/data-sharing-requestprocess.html.

Open Access. This article is licensed under a Creative Commons Attribution-NonCommercial 4.0 International License, which permits any non-commercial use, sharing, adaptation, distribution and reproduction in any medium or format, as long as you give appropriate credit to the original author(s) and the source, provide a link to the Creative Commons licence, and indicate if changes were made. The images or other third party material in this article are included in the article's Creative Commons licence, unless indicated otherwise in a credit line to the material. If material is not included in the article's Creative Commons licence and your intended use is not permitted by statutory regulation or exceeds the permitted use, you will need to obtain permission directly from the copyright holder. To view a copy of this licence, visit http:// creativecommons.org/licenses/by-nc/4.0/.

\section{REFERENCES}

1. Scott DL, Wolfe F, Huizinga TW. Rheumatoid arthritis. Lancet. 2010;376:1094-108.

2. van der Helm-van Mil AHM, Verpoort KN, Breedveld FC, Toes RE, Huizinga TW. Antibodies to citrullinated proteins and differences in clinical 
progression of rheumatoid arthritis. Arthritis Res Ther. 2005; 7:R949-58.

3. Hecht C, Englbrecht M, Rech J, et al. Additive effect of anti-citrullinated protein antibodies and rheumatoid factor on bone erosions in patients with RA. Ann Rheum Dis. 2015;74:2151-6.

4. Singh JA, Saag KG, Bridges SL Jr, et al. 2015 American College of Rheumatology guideline for the treatment of rheumatoid arthritis. Arthritis Care Res. 2016;68:1-26.

5. Smolen JS, Landewe RBM, Bijlsma JWJ, et al. EULAR recommendations for the management of rheumatoid arthritis with synthetic and biological disease-modifying antirheumatic drugs: 2019 update. Ann Rheum Dis. 2020;79:685-99.

6. Lv Q, Yin Y, Li X, et al. The status of rheumatoid factor and anti-cyclic citrullinated peptide antibody are not associated with the effect of anti-TNFalpha agent treatment in patients with rheumatoid arthritis: a meta-analysis. PLoS ONE. 2014;9: e89442.

7. Sokolove J, Schiff M, Fleischmann R, et al. Impact of baseline anti-cyclic citrullinated peptide- 2 antibody concentration on efficacy outcomes following treatment with subcutaneous abatacept or adalimumab: 2-year results from the AMPLE trial. Ann Rheum Dis. 2016;75:709-14.

8. Huizinga TWJ, Connolly SE, Johnsen A, et al. Effect of anti-cyclic citrullinated peptide 2 immunoglobulin $\mathrm{M}$ serostatus on efficacy outcomes following treatment with abatacept plus methotrexate in the AVERT trial. Ann Rheum Dis. 2015;74(Suppl 2): 234-5.

9. Harrold LR, Litman HJ, Connolly SE, et al. Effect of anticitrullinated protein antibody status on response to abatacept or antitumor necrosis factoralpha therapy in patients with rheumatoid arthritis: a US national observational study. J Rheumatol. 2018;45:32-9.

10. Gottenberg JE, Courvoisier DS, Hernandez MV, et al. Brief report: association of rheumatoid factor and anti-citrullinated protein antibody positivity with better effectiveness of abatacept: results from the Pan-European registry analysis. Arthritis Rheumatol. 2016;68:1346-52.

11. Courvoisier DS, Chatzidionysiou K, Mongin D, et al. The impact of seropositivity on the effectiveness of biologic anti-rheumatic agents: results from a collaboration of 16 registries. Rheumatology (Oxford). 2021;60:820-8.

12. Harrold LR, Litman HJ, Connolly SE, et al. Comparative effectiveness of abatacept versus tumor necrosis factor inhibitors in patients with rheumatoid arthritis who are anti-CCP positive in the United States Corrona Registry. Rheumatol Ther. 2019;6:217-30.

13. (FDA) UFaDA. Drug Approval Package: Orencia (Abatacept) Injectible (IV). 2006. https://www. accessdata.fda.gov/drugsatfda_docs/nda/2005/ 125118_s0000_OrenciaTOC.cfm. Accessed 17 Feb 2021.

14. Hochberg MC, Chang RW, Dwosh I, Lindsey S, Pincus T, Wolfe F. The American College of Rheumatology 1991 revised criteria for the classification of global functional status in rheumatoid arthritis. Arthritis Rheum. 1992;35:498-502.

15. Pratt AG, Isaacs JD. Seronegative rheumatoid arthritis: pathogenetic and therapeutic aspects. Best Pract Res Clin Rheumatol. 2014;28:651-9.

16. Cappelli LC, Palmer JL, Kremer J, Bingham CO 3rd. Tocilizumab treatment leads to improvement in disease activity regardless of CCP status in rheumatoid arthritis. Semin Arthritis Rheum. 2017;47:165-9.

17. Katchamart W, Koolvisoot A, Aromdee E, Chiowchanwesawakit P, Muengchan C. Associations of rheumatoid factor and anti-citrullinated peptide antibody with disease progression and treatment outcomes in patients with rheumatoid arthritis. Rheumatol Int. 2015;35:1693-9.

18. Derksen V, Huizinga TWJ, van der Woude D. The role of autoantibodies in the pathophysiology of rheumatoid arthritis. Semin Immunopathol. 2017;39:437-46.

19. Ajeganova S, van Steenbergen HW, Verheul MK, et al. The association between anti-carbamylated protein (anti-CarP) antibodies and radiographic progression in early rheumatoid arthritis: a study exploring replication and the added value to ACPA and rheumatoid factor. Ann Rheum Dis. 2017;76: 112-8.

20. Verpoort KN, Jol-van der Zijde CM, Papendrechtvan der Voort EA, et al. Isotype distribution of anticyclic citrullinated peptide antibodies in undifferentiated arthritis and rheumatoid arthritis reflects an ongoing immune response. Arthritis Rheum. 2006;54:3799-808.

21. McInnes IB, Schett G. Pathogenetic insights from the treatment of rheumatoid arthritis. Lancet. 2017;389:2328-37.

22. McInnes IB, Buckley CD, Isaacs JD. Cytokines in rheumatoid arthritis: shaping the immunological landscape. Nat Rev Rheumatol. 2016;12:63-8. 
23. Alemao E, Postema R, Elbez Y, Mamane C, Finckh A. Presence of anti-cyclic citrullinated peptide antibodies is associated with better treatment response to abatacept but not to TNF inhibitors in patients with rheumatoid arthritis: a meta-analysis. Clin Exp Rheumatol. 2020;38:455-66.

24. Teng YK, Levarht EW, Hashemi M, et al. Immunohistochemical analysis as a means to predict responsiveness to rituximab treatment. Arthritis Rheum. 2007;56:3909-18.

25. Fabris M, De Vita S, Blasone N, et al. Serum levels of anti-CCP antibodies, anti-MCV antibodies and RF IgA in the follow-up of patients with rheumatoid arthritis treated with rituximab. Auto Immun Highlights. 2010;1:87-94.

26. Bird P, Hall S, Nash P, et al. Treatment outcomes in patients with seropositive versus seronegative rheumatoid arthritis in Phase III randomised clinical trials of tofacitinib. RMD Open. 2019;5: e000742.

27. Pope JE, Keystone E, Jamal S, et al. Persistence of tofacitinib in the treatment of rheumatoid arthritis in open-label, long-term extension studies up to 9.5 years. ACR Open Rheumatol. 2019;1:73-82.

28. Curtis JR, Chen L, Bharat A, et al. Linkage of a deidentified United States rheumatoid arthritis registry with administrative data to facilitate comparative effectiveness research. Arthritis Care Res (Hoboken). 2014;66:1790-8.
29. FDA. Xeljanz (tofacitinib) Tablets. 2012. https:// www.accessdata.fda.gov/drugsatfda_docs/nda/ 2012/203214Orig1s000TOC.cfm. Accessed 17 Feb 2021.

30. Choy EH, De Benedetti F, Takeuchi T, Hashizume M, John MR, Kishimoto T. Translating IL-6 biology into effective treatments. Nat Rev Rheumatol. 2020;16:335-45.

31. Tymms K, Butcher B, Smith T, Littlejohn G. Impact of anti-citrullinated protein antibody on tumor necrosis factor inhibitor or abatacept response in patients with rheumatoid arthritis. Eur J Rheumatol. 2020;8:67-72.

32. Harrold LR, Bryson J, Lehman T, et al. Association between baseline anti-cyclic citrullinated peptide antibodies and 6-month clinical response following abatacept or TNF inhibitor treatment: a real-world analysis of biologic-experienced patients with RA. Rheumatol Ther. 2021;8:937-53.

33. Gardette A, Ottaviani S, Tubach F, et al. High antiCCP antibody titres predict good response to rituximab in patients with active rheumatoid arthritis. Jt Bone Spine. 2014;81:416-20.

34. Pongratz G, Frieser R, Brinks R, et al. Association between autoantibody level and disease activity in rheumatoid arthritis is dependent on baseline inflammation. Clin Exp Rheumatol. 2020;38:691-8. 